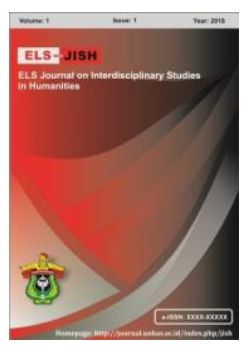

ELS-JISH

ELS Journal on Interdisciplinary Studies on Humanities

Volume 2 Issue 1, 2019

ISSN (print) : 2621-0843

ISSN (online) : 2621-0835

Homepage : http://journal.unhas.ac.id/index.php/jish

\title{
Dividual Turn: A Comparative Study of the Worldviews of the Japanese and the Melanesian Folks
}

\author{
Naruhiko Mikado ${ }^{1}$ \\ track.and.basketball@gmail.com $^{1}$
}

\begin{abstract}
This study has three aims: the first is to illuminate the transformation in the minds of the Japanese people after the catastrophic earthquake in 2011-namely, the collective movement to reappraise the worth of bonds and connections between/among people. The second is to show that the ongoing spiritual change has a number of similarities with the worldview of the Melanesian folk which Marilyn Strathern analysed with the concept of "dividual". The third is to generalize diverse insights which the two cases suggest and thus to seek a fresh way to see people and those relations which bridge over them. The argument begins with a discussion to prove the point of the first aim, then the second, and, after referring to what is not dealt with for future research, concludes by demonstrating that of the third. The contribution which this study will make for interdisciplinary scholarship is that it attests a literary text and an anthropological study can be employed to derive a philosophical discourse.
\end{abstract}

Keywords: 3.11, Japan, dividual

How to cite: Naruhiko, M. (2019). Dividual Turn: A Comparative Study of the Worldviews of the Japanese and the Melanesian Folks. ELS Journal on Interdisciplinary Studies in Humanities, 2(1), 66-74.

\section{Introduction}

In recent years one has had many opportunities to see Japan, my country, being dealt with in a variety of discussions, whether the topic be about its culture, history, or politics. The nation still maintains a competitive as well as a stable economic foundation, and, for better or worse, is regarded as an important political power in the Asian-Pacific region. In addition, it is going to host the Group of 20 summit in Osaka this year, and the Olympic Games will be held in Tokyo next year, which is estimated to occasion a decent upsurge in the number of visitors from foreign countries. Allowing for these factors, it would not be wide of the mark to count the nation for an active member of the international community.

However, I presume that Japan is a fairly remote country in various senses for many people who live in different cultural environments. As one can observe by a world globe, it is geographically isolated, surrounded on all sides by the sea; in linguistic terms, there is no language that can be classified into the same linguistic family to which Japanese belongs. Therefore, it seems that what country Japan is like and how the Japanese folk act

\footnotetext{
${ }^{1}$ Osaka University, Japan
} 
and think are unknown as yet to Asian, African, European, Oceanian, and American peoples.

It is widely known and true that Japan after the Meiji Restoration in 1868 modernized itself at a breakneck pace to catch up with the Western countries. It avidly absorbed not only their technological advancements but also intellectual conceptions such as theological notions and philosophical systems developed there. Amongst the influential imported ideas is individualism (Fukazawa, 2018, p. 53), which could be roughly defined as a view that regards each person as the most fundamental and valuable entity in the world. One could easily recognize that the concept is ingrained in the Japanese society to some degree from the fact that the people not seldom use the expression "self-responsibility", and that a person is generally considered to be full-fledged when she/he becomes economically independent of her/his parents and begins to lead a single life.

Still, one ought not to disregard the fact that the women and men on the Japanese Archipelago had lived for countless generations with a set of thinking and value systems dissimilar from that of the Western people. In days of yore, our ancestors are presumed to have embraced an animistic worldview (Riku \& Go 2011), and then a perspective starkly influenced by Buddhistic principles was grafted onto it during medieval times (Takemitsu 2018). As is well known, animism is a term to denote "an ontology wherein humans and nonhumans reputedly have the same kind of interiority but are differentiated by the bodies they inhabit" (Descola 2011, p. 216), and Buddhism is a religion which places particular emphasis upon a diversity of causal relationships (which the believers call engi). Both of them are unlike Christian tenets and modern thoughts of the West. There is no doubt that the current Japanese people are, at least partially, defined by these substrata, and thus it would be impossible to understand the people without contemplating the factors seriously.

For the past few decades, Japan has gone through an array of occurrences which shook the people there in innumerable ways. An array of natural disasters are the most conspicuous examples, of which the calamitous earthquake in 2011 signalizes itself. It dispatched tens of thousands of my compatriots, and even those who survived it have had their lives transformed. It would be natural that such a catastrophe makes no small impact upon an established pattern of thought and prods the affected people to ruminate over themselves reflectively. Probably because of the tide, several phenomena which could be counted as the renaissance of the "old" philosophies are coming about at the moment. Of crucial importance is that those discourses which accentuate "bonds" and "connections" are rapidly increasing in an assortment of spheres, whereas talks which stress one's own responsibility are losing momentum.

Nevertheless, neither anthropologists nor sociologists have carried out a comprehensive scholarly examination into the tendency so far. This may be partly ascribed to the fact that both the humanities and the social sciences are on the decline in Japan, yet the principal cause would be that the Japanese citizens in general have an aversion to handling a tragedy in the near past dispassionately as an object; to put it in another way, they respect the sensitivities of those involved in the occasion, whether directly or indirectly, so sincerely that they would not like to inspect it as if from the outside.

But, while paying due respect to the feelings of my compatriots, I will attempt to conduct a philosophical investigation into part of the problem. For the clarity of the argument, I will focus on the nature of the transformation that the worldview of the 
Japanese has undergone in the aftermath of 3.11. The argument would go as follows: in the beginning, by analyzing a text of the late local writer, Tatsuaki Hashimoto, I will show that the Japanese people recently begin to esteem a person as inseparable from ties which link them with others. Second, I will introduce a concept of a person as dividual that Marilyn Strathern advanced through anthropological research into Melanesia, which holds that an individual can be divided, in order to point out that the present turn in the minds of the Japanese folk bears a striking similitude with it and could be better comprehended with the aid of the concept. Third, a few limitations of their arguments will be pointed out. In closing, what one could learn from these discussions will be explored.

Idealistic as it would sound, the eventual purpose of this paper is, through a metacognitive review of my/our structure of thought, to facilitate the understanding of my folk in this more and more globalized world in which a myriad number of non-identical actors take part and cooperate, and to propose a fresh perspective through which one could have a chance to broaden her/his horizons.

\section{Rise of Bonds and Connections in Japan after 3.11}

As stated above, these years have seen an increase in the use of the words like "bonds" and "connections" throughout Japan. While some people may highlight their attachment to their hometown, others would underscore their ties with their partner or family; at any rate, as Ohashi clarified, such articulations have increased especially after the ruinous earthquake on March 11 in the year of 2011. Those who live in Japan would meet or hear such a phrase at least once a day. On the contrary, nowadays Japanese insist much less frequently upon the importance of doing things at one's own risk as a responsible individual. The contrast is intriguing: the distinctively modern idea of a free, independent person appears to be eclipsed by an outlook which emphasizes various forms of associations and links, which may be regarded as a shackling opinion in a culture that esteems each woman and man as an individual agent.

Tatsuaki Hashimoto, a writer and editor of a local newspaper who died 2017, is the figure who, albeit in a rather essayistic and desultory touch, furnished probably the most perceptive description of the psychological shift in the hearts of his compatriots which revalues linkages more than individualism. That his view, which I discuss in this section, is not an idiosyncratic quirk but one which captures a common opinion among his fellow nationals could be discerned from a series of warm acceptances which his writings have received and his steady presence across the media.

Wondering why words such as bonds and connections have increasingly voiced by his compatriots, he speculates that after the tremor, they began to reconsider the mortality of human beings as their own problem and to think of themselves not as independent entities but as beings indivisible from the nexus which exist at diverse levels between them (Hashimoto, 2012).

Incidentally, the term individual originally meant "one in substance or essence", "forming an indivisible entity" or "indivisible" ("Individual," 2014). In the course of time, on account of an influence of Christianity (i.e. the belief that a person also must be a unified existence when she/he is confronted with the perfect and absolute Supreme Being) and of the development of logic as a discipline (that posits that an individual is a being which cannot be split anymore), it procured the sense similar to that of indivisible person in the modern era. Then, as the ancient caste system collapsed as a result of modernization, the notion that an individual as an indivisible entity is the minimum unit of society has 
emerged-an idea which predicates that a human community, be it an empire or a county, can be divided into ever smaller components (towns, families, etc.) and that the most basic element which composes every group is an individual.

This stance would inevitably presuppose that a connection between individuals can be severed. Although this may look like a theorization of a matter of fact, Hashimoto, mulling over the spiritual circumstances of Japan, suspects that the theory does not always apply; he muses that "an individual can be divided by relations with other beings".

For example, a person displays a different profile depending upon a situation: when one is on a date with her/his lover, she/he would exhibit a profile which is not the same as that which her/his parents would see.

Namely, a person owns a variety of profiles (miens, auras, gestures), but it is not proper to dismiss this by simply assuming that the person behaves according to the role, or rather performs in it. Such a conjecture is just the refashioning of functionalistic, oldfashioned social anthropology which kidded itself that an (indivisible) individual would put on a different mask to suit the time and place. In lieu thereof, each of us has become the person who she/he is owing to influences of other existences, incessantly being reshaped in points both conspicuous and minute. The person that I become/am when I'm with my lover could not exist without her or the relation with her, and vice versa. The self is not immanent exclusively in an individual. Bits of the self are permeated in other beings and the relations.

In this theoretical sense, an individual can be considered partible by relations with others, having resultantly a diversity of profiles. Still, we should mark that each of the relations themselves, be it with a lover, a parent, or a friend, is unable to be divided. The self that a person is when she/he is with a friend must require the friend to be the self. If it were separated, it would follow that the friend must vanish; then the self that the person has presented to the friend would "no longer be able to live":

Though a person has a lot of profiles, those are not readily concocted at her/his independent will. Instead, they generate themselves always with a medley of relations which the person has with other beings. For instance, the sorrow which a mother who lost her child in this catastrophic earthquake would come from not only the disappearance of the child, but also from the fact that the self as which she had led life with the child would also no longer be able to live. (Hashimoto, 2012, pp. 12-13).

When one loses a connection with another, she/he will simultaneously be deprived of part of the self. Only because there are other beings that have bonds with me in variegated manners, I can be what I am which is composed of plural I-s. The self is becoming itself in the links.

Hashimoto (2012) concludes his essay by hypothesizing that what the Japanese are now doing by reevaluating bonds and connections is an attempt to regenerate "those ties which are indispensable for them to be themselves" (p. 13). As I indicated earlier, he does not delve into or elaborate upon the subject any longer, and, as is inevitable when a generalization is made, his theory fails to account for other recent trends in Japanese society which seem rather congenial to individualism. But, his discussion on the Japanese minds after 3.11, sketchy though the primary text may be, indeed captures a mainstream 
orientation and is genuinely valuable in that it provides a counterpoint through which one could look at the notion of a person as an individual in a new light.

\section{Dividual Person in Melanesia}

Marilyn Strathern, a British anthropologist, also set forth a thesis that a person could be partible, employing the term dividual to expound upon the view of humans held among the Melanesian folk. ${ }^{2}$ Whereas Hashimoto brooded and theorized based mainly upon the intellectual current of his contemporaneous compatriots, Strathern developed her theory through a succession of anthropological studies into societies in Melanesia, including that of New Guinea, her chief focus. Besides the methodical one, it may be possible to identify some other differences between them; yet they look together in the same direction, and when juxtaposed with each other, they would present many insights through which one could rethink the idea of an individual person with a more impartial outlook.

In Melanesia, according to Strathern, a person is regarded as a being which encompasses inside her/him all types of relations and connections with other people, communities, and natural environments. She dubbed such a view dividual:

Melanesian persons are as dividually as they are individually conceived. They contain a generalized sociality within. Indeed, persons are frequently constructed as the plural and composite site of the relationships that produced them. The singular person can be imagined as a social microcosm.... By contrast, the kinds of collective action that might be identified by an outside observer in a male cult performance or group organization, involving numbers of persons, often presents an image of unity. (Strathern, 1988, p.13)

She further remarks that Melanesian folk consider a woman and a man to be an androgynous, manifold existence, saying, "[E]ach male or female form may be regarded as containing within it a suppressed composite identity; it is activated as androgyny transformed" (Strathern, 1988, p. 14). However, the person is sometimes requested to assume one gender according to the time and circumstances. For example, in a marriage, the bride is deemed as the embodiment of multiple relations not only with the members of her clan but also between her clan and that of the bridegroom. Then, in this matrimony, those of her clan including its male head become "female" to the counterparts of the bridegroom, regardless of their biological sex. Likewise, the bridegroom and his kinship group become "male". When one surveys the situation from the standpoint of the leader of the bride's clan, he is/becomes "female" on account of the relation with a woman in his group; if a man of his sib gains a wife, the leader is/becomes "male" due to the relation with the man. In a variety of incidents which build a new connection with others, those androgynous people alter their gender from one to the other. What Strathern intends to foreground is not that a relation has priority over a person, but that each of the two has an equal agency to define the other.

The exposition above might be too convoluted to grasp the significance in one reading; yet, one would understand her aim of presenting a worldview radically atypical for European people, when she/he knows the traditional Western idea of humans which Strathern wanted to challenge, and the social and historical contexts that goaded her to shoulder such an arduous task.

2 One should note that the term dividual itself was not her invention. It was originally coined by Mariott and Inden (1977) in their study of South Asian societies. They used it to denote Hindus' view of humans which is dissimilar from that of the West. But the word had not attained much circulation then. 
The opinion about human societies which was dominant in the UK at the time was largely set by Radcliffe-Brown, who laid the foundation of social anthropology in the country. As Aurora succinctly put it, he "used the word 'person' to refer to the basic unit of society. 'Person' is seen through an individual" (Aurora, 1966, p. 93); consequently, according to the view, any relation which links a person with another is outside the person, so that she/he can break it at any moment theoretically. Additionally, when Strathern published The Gender of Gift, her seminal work, in 1988, the British society was filled with those phenomena which would rend social associations and propel a view emphasizing individuals, with its incarnation Thatcher symbolically stating, "There is no such thing as society. There are individual men and women" (Keay, 1987, p. 9).

In the times when links, bonds, and connections amongst people were severed in a rush, Strathern tried to voice dissent to the tide of the era and to introduce a perspective upon which people could relativize their established frame of thought. She is now counted as an important standard bearer of the so-called "Ontological Turn" of anthropology along with Bruno Latour, Viveiros de Castro and Roy Wagner, who collectively hurl defiance at the expanding predominance of Western values. To add to the anthropological intention of promoting an understanding of another people, Strathern sought to prevent the individualistic tendency from becoming uncontrollable by depicting a community which, albeit technologically unsophisticated, went smoothly with a philosophical framework that would not necessarily prioritize an individual to a relation, emblematically calling the way dividual.

As can be discerned, the ongoing mental transformation amongst the Japanese nation about which Hashimoto speculated shares some salient commonalities with the Melanesian worldview which Strathern elucidated with the conception of dividual: both of them fling down the gauntlet at the naive belief that an individual is the most fundamental, solid unit and thus the fate of every relation depends upon her/him. In lieu of the view, they demonstrated that the self of an individual is actually disseminated in the shape of links which connect her/him with others, while the relations themselves could have leverage with the individual. The idea that relations are just as fundamental as individuals may strike one who has grown in a more or less modern/Western milieu as counterintuitive; yet, now it would be remiss of us to turn our back upon another possibility that the two indicated in their own ways.

\section{Problems of the Arguments of Hashimoto and Strathern}

Until the last part, I have quite favourably outlined how Hashimoto and Strathern suggested that people could see a person differently by deeming relations as constitutive of the self. However, it would be incumbent on me to designate their drawbacks in order to ascertain what is left for future investigations. Although one might adduce other defects, two problems stand out in particular.

The first of them is that they do not pay much attention to the genesis of a relationi.e. the moment at which a person meets another being and the self is modified to a greater or lesser extent. For those who have trained themselves for structuralist lines of thinking, both of the two would come across as being content to have discussed existing associations. In this sense, they may be regarded as insufficiently liberal in that the minds 
of the Japanese folk and the Melanesian worldview that they described would not seem open to the alien others.

As to this point, it is Lévi-Strauss who propounded a really interesting insight. In The Origin of Table Manners, the third piece of his massive four-volume work Mythologiques, he states that Native Americans have conceived that every one of them has a hollow and a site where an alien being ensconce itself, and explains that the people do not saturate themselves and always have a space where a new relation can be formed (Lévi-Strauss 1968) This would have a profound theoretical potential based on which one can inquire her/his preconceptions about the self, but here I will desist from probing into it further since similar cases can be found throughout his colossal oeuvre and it must demand a booklength study to handle it sufficiently.

The second one is that they do not mention a fact that a being could have a relation with itself within itself; namely, the two treat only those relations which one forms with others. One could locate an obdurate vestige of modern/Western individualism in their presupposition that a relation must necessitate another being outside itself.

Michel Foucault, another giant of the structuralist pantheon, can be consulted to tackle this difficulty. His productions may not be rich in those discourses which concern themselves with links with others; still, his discourses about the subject, especially those in The Hermeneutics of the Subject, squared up to the problem alluded to above: one's complex relations with oneself. His contention that a person is often obliged to modify a planned course of action so as to match the real/current self with the rational/ideal self implies that, in a manner different from that of Hashimoto, the self is not a constant entity, but a motion-a becoming, amending itself not only by bonds with other beings, but also by connections inside itself (Foucault, 2005).

It is certain that the problems that I brought forward are grave ones, and, if one would like to analyze them rigorously, she/he should spend at least an entire semester to attain a solution or something. Nevertheless, though I restricted myself to outlines here, we should address ourselves to the studies as soon as possible, because pretermitting them would mean that we will deliberately miss opportunities to widen our outlook upon the intricate correlations between/amongst relationships.

Besides, those resultant insights which could be drawn by enquiring into these matters would never be incompatible with those Hashimoto and Strathern proposed. Rather, they will receive a fair number of benefits each other, and may collectively create a possibility for one to formulate another worldview. I do not gainsay that this prospect has a smack of idealistic, or even Hegelian optimism; still, almost no one would deny the value of seeking a better image of the world.

\section{Conclusion}

If I ended the argument with the last section, readers would probably derive diverse pieces of wisdom from the arguments of Hashimoto and Strathern which I briefed. Yet, as a bid to be an examination of anthropological philosophy, this paper has an obligation to verbalize, or rather conceptualize some general precepts which are universally intelligible. 
It is definitely wrong to reduce their discourses to a banal denial of individualism. That is just an inversion of the existing hierarchy and would lead to no constructive suggestion. The most outstanding insight which the discussions of the two writers afforded is that a person, other beings, and the relations which bridge over them are by no means separable from one another; in other words, a portion of each of the three is distributed into the other two, and resultantly every one of them relies on both itself and the other two for its existence. The lesson that we should glean from these facts is that, platitudinous as it may sound, even a seemingly reasonable view that a person is an individual, unified entity which cannot be severed could be questioned by taking in a different point of view. Hashimoto showed that the chance to review oneself might lie near at hand, while Strathern proffered evidence that one could have it in a radically different sphere.

No one would be able to upturn the current tide of globalization. In this state, what we should do is never to shut ourselves up in a comfortable space where a sham sense of unity based on prejudices against others is rampant and homogeneous beings merely cajole one another. Instead, we must actively embark for a world which may baffle us first but whose relations with us would enable us to refine the self in a way which we could not have anticipated, because, to borrow a saying in a drama, "the world only spins forward" (Kushner, 1994, p. 99.)

\section{References}

Aurora, G. (1966). Open systems of consciousness. Sociological Bulletin, 15(1), 90-108.

Descola, P. (2010). Wholes to collectives. In T. Otto \& N. Bubandt (Eds.), Experiments in holism: Theory and practice in contemporary anthropology. (pp. 209-226). Malden, MA: Wiley-Blackwell.

Foucault, M. (2005). The hermeneutics of the subject: Lectures at the Collège de France 1981-82. (G. Burchell, Trans.). New York, NY: Palgrave Macmillan.

Fukazawa, T. (2018). A research in a period of introduction of Marxism and Marxian economics into Japan. The Bulletin of Yamanashi Gakuin Center of University Lifelong Learning Activities, 22, 49-69. Retrieved from https://ygu.repo.nii.ac.jp/?action=repository_uri\&item_id=3545\&file_id=22\&file_no=1

Hashimoto, T. (2012, March 11). Opinion. Shimotsuke Shimbun, pp. 12-13.

Individual. (2014). In The Oxford English dictionary (3d edition). Retrieved from http://www.oed.com/view/Entry/94633

Keay, D. (1987, September 23). Interview with Margaret Thatcher. Woman's Own. Thatcher Archive: COI Transcript

Kushner, T. (1994). Angels in America part two: Perestroika. New York, NY: Teatre Communications Group.

Lévi-Strauss, C. (1968). The Origin of Table Manners (J. Weightman \& D. Weightman, Trans.). New York: Harper \& Row, Publishers. 
Riku, B., \& Go, M. (2011). The achetype of the idea of symbiosis: a quest for the Japanese view of nature. Bulletin of Aichi Institute of Technology, 46, 13-18. Retrieved from http://aitech.ac.jp/lib/electricdoc/files/46/A02.pdf

Strathern, M. (1988). The gender of the gift: Problems with women and problems with society in Melanesia. Berkeley: University of California Press.

Takemitsu, M. (2018). A study of Shinto thought: The birth of the ancient Japanese state and the ideology of Wa. The MGU journal of liberal arts studies: Karuchuru, 12(1), 115.

Retrieved

from https://meigaku.repo.nii.ac.jp/?action=repository_uri\&item_id=2685\&file_id=18\&file_n $0=1$

Ohashi, R. (2012). Communicative features in the copies of the campaigns for restoration from the great east japan earthquake. Journal of The Open University of Japan, 29, 55-62. Retrieved from https://ouj.repo.nii.ac.jp/?action=repository_uri\&item_id=7559\&file_id=22\&file_no=1 